\title{
KRISIS CITRA PENYELENGGARAAN EVENT JAKARTA FAIR UNTUK MENGEMBALIKAN KONSEP MERAKYAT
}

\author{
Lidia Wati Evelina \\ Marketing Communication Department, Faculty of Economic and Communication, BINUS University \\ Jln. K.H. Syahdan No. 9, Palmerah, Jakarta Barat 11480 \\ lidiaevelina@yahoo.com
}

\begin{abstract}
Research goal is to analyze the crisis of event implementation image of Jakarta Fair 2013, done by JIExpo which changing from people orientation to business orientation. This research is motivated by the desire of the city government to restore the original concept of the event held for the people. Research used qualitative method approach to find out more about the communications made by the city government. Information and data were obtained through interviews conducted by the visitor and direct observation in the field. Triangulation was used to test the validity of research data. Source selection was done using purposive sampling technique. The analysis used the analysis of the reduction is to collect, dispose of, and process the information and then displays the data and drawing conclusions. Results achieved that the promotional activities undertaken by JIEXPO are able to attract many people's attention to come even though it is located quite far away and charged. However, the party criticized the government organization that is not after the populist concept. Conclusion from the research organization of this annual event remains one of alternative entertainment for society in general and in particular to the people of Jakarta and surrounding areas. However, the need to accommodate the delivery of PT JIEXPO small businesses to be able to participate in the annual event. There needs to be an open conversation that is a win-win solution between PT JIExpo with the city government.
\end{abstract}

Keywords: communication crisis, events, Jakarta Fair

\begin{abstract}
ABSTRAK
Penelitian bertujuan untuk menganalisis krisis citra penyelenggaraan Jakarta Fair 2013 yang beralih dari konsep merakyat menjadi mementingkan pebisnis. Penelitian dilatarbelakangi keinginan Pemprov DKI untuk mengembalikan konsep awal diadakannya event tersebut untuk rakyat. Pembahasan penelitian menggunakan teori komunikasi verbal dan nonverbal, konsep special event, konsep crisis dan citra. Metode yang digunakan adalah metode kualitatif untuk mengetahui lebih dalam mengenai komunikasi yang dilakukan oleh Pemprov DKI. Informasi dan data diperoleh melalui wawancara yang dilakukan kepada pengunjung dan melakukan observasi langsung di lapangan. Triangulasi sumber digunakan untuk menguji keabsahan data penelitian. Pemilihan sumber dilakukan dengan menggunakan teknik purposive sampling. Analisis yang digunakan yaitu analisis reduksi, yaitu mengumpulkan, membuang, dan mengolah informasi kemudian menampilkan data dan melakukan penarikan simpulan. Hasil yang dicapai yaitu kegiatan promosi yang dilakukan oleh JIEXPO mampu menarik banyak perhatian masyarakat untuk datang meskipun letaknya cukup jauh dan dikenakan biaya tiket masuk. Namun pihak Pemprov mengkritik penyelenggaraan yang tidak seusai dengan konsep merakyat. Simpulan penelitian yang dilakukan penyelenggaraan event tahunan ini masih menjadi salah satu alternatif hiburan untuk mayarakat pada umumnya dan khususnya untuk masyarakat Jakarta dan sekitarnya. Meskipun begitu pihak penyelenggaran PT JIEXPO perlu mengakomodasi pengusaha kecil untuk dapat berpartisipasi dalam event tahunan tersebut. Pembicaraan terbuka yang bersifat win-win solution diperlukan antara PT JIExpo dengan pihak Pemprov DKI.
\end{abstract}

Kata kunci: krisis komunikasi, event, Jakarta Fair 


\section{PENDAHULUAN}

Keberadaan Pekan Raya Jakarta (PRJ) di Kemayoran kembali dipermasalahkan. Jokowi, Gubernur DKI, menghendaki PRJ dipindahkan kembali ke Monas seperti sebelum 1992. Jokowi menilai PRJ yang sekarang ini jauh dari rakyat. PRJ hanya menonjolkan kepentingan bisnis dan mengejar kepentingan komersial saja. Padahal PRJ seharusnya bertujuan untuk menghibur warga Jakarta.

Winarno (2013) menjelaskan bahwa pengunjung Pekan Raya Jakarta makin hari makin meningkat. Hal ini dibuktikan event yang pertama kali diselenggarakan pada 1968 itu menyedot pengunjung sekitar 1,4 juta orang merupakan angka yang fantastis pada masa itu. Kala itu acara yang digelar pun unik dengan mengadakan pemilihan ratu waria. Pemilihan diikuti 151 peserta dan dapat dikatakan cukup banyak kala itu.

Kemudian, masih dalam Winarno (2013), dikatakan bahwa Pekan Raya Jakarta 1969 memecahkan rekor penyelenggaran PRJ terlama karena memakan waktu penyelenggaraan 71 hari. PRJ pada umumnya berlangsung 30-35 hari. Bahkan Presiden AS pada waktu itu, Richard Nixon, datang ke Indonesia, sempat mampir ke Jakarta Fair 1969. Ia berhenti di sebuah stan dekat Syamsuddin Mangan Plaza, sempat melambai-lambaikan tangan ke pengunjung dan karyawan Jakarta Fair 1969.

Permasalahan yang dibahas dalam penelitian adalah tentang alasan konsep dan tempat PRJ diubah kembali oleh Pemprov DKI Jakarta. Sementara tujuan penelitian adalah untuk mengetahui adanya perubahan yang terjadi dari konsep PRJ yang beralih ke kepentingan pebisnis. Citra PRJ mengalami krisis dari semula berkonsep merakyat beralih menjadi konsep yang mengutamakan kepentingan pebisnis. Penyelenggaraan PRJ atau Jakarta Fair dari tahun ke tahun mulai mengalami perkembangan pengunjung dan pesertanya bertambah dan terus bertambah. PRJ dari sekadar pasar malam bermutasi menjadi ajang pameran modern yang menampilkan berbagai produk. Areal yang dipakai juga bertambah, dari yang hanya tujuh hektar di kawasan Monas, kini semenjak 1992 dipindah ke Kawasan Kemayoran, Jakarta Pusat, menempati area seluas 44 hektar. Sejak saat itu PRJ selalu digelar di Kemayoran dan dikelola oleh PT JIExpo.

Namun disayangkan, perpindahan lokasi menjadikan pergeseran konsep pula. PRJ dari yang semula lebih beroritentasi ke masyarakat, tetapi setelah menempati lahan di kawasan Kemayoran, berubah jadi lebih mementingkan pebisnis besar ketimbang pengusaha industri kecil. Lantas di bawah kepemimpinan Gubenur Jakarta, Joko Widodo, konsep ingin dikembalikan ke tujuan semula, yaitu mengembangkan perekonomian rakyat.

Hasil dari penelitian ini diharapkan menjadi masukan bagi penyelenggara Pekan Raya Jakarta, dalam hal ini PT JIExpo, dan Pemprov DKI Jakarta. Kedua belah pihak agar menyadari konsep yang sesuai dengan keinginan masyarakat pengunjung. Perbedaan konsep tentu akan menimbulkan pertentangan bagi keduanya sehingga akan terjadi krisis dalam penyelenggaraan Pekan Raya Jakarta tersebut.

\section{METODE}

Penelitian membahas konsep Pekan Raya Jakarta yang sudah berubah menggunakan kajian komunikasi verbal dan nonverbal, konsep special event dan konsep krisis, serta konsep citra dari Pekan Raya Jakarta tersebut. Metodologi yang digunakan adalah metodologi kualitatif deskriptif yang 
menggambarkan tentang upaya pemerintah DKI untuk mengadakan event yang mengusungkan tentang budaya Betawi. Metodologi kualitatif ini digunakan untuk mengarahkan penelitian dengan membuat pertanyaan yang bersifat retoris atau argumen tentang temuan dari penelitian yang dilakukan dan tidak tergantung pada analisis statistik seperti yang digunakan pada metodologi penelitian kuantitatif (West \& Turner, 2007). Sedangkan Menurut Moleong(2004), metodologi kualitatif bukan berupa angkaangka, melainkan merupakan suatu data yang berasal dari wawancara, observasi di lapangan, dokumen pribadi maupun dokumen perusahaan yang dapat mendukung tujuan dari penelitian yang mencocokkan realitas dan teori yang digunakan.

Pengumpulan data dilakukan dengan mengadakan observasi dan wawancara kepada masyarakat pengunjung Jakarta Fair 2013 serta data sekunder dari artikel media online. Dalam penelitian ini data diperoleh dari data primer dan sekunder. Data primer diperoleh dari observasi langsung yang dilakukan di lapangan dengan mengunjungi Pekan Raya Jakarta 2013. Peneliti dapat melihat secara langsung dan nyata keadaan yang terjadi di lapangan sehingga memperoleh tambahan pengalaman dan juga melengkapi penelitian yang dilakukan.

Data primer juga diperoleh dari hasil wawancara yang dilakukan dengan pihak manejemen PT JIExpo, khususnya bagian yang turut serta dalam perencanaan dan pelaksanaan kegiatan promosi yang dilakukan. Menurut Herdiansyah (2012) mengungkapkan bahwa wawancara semistruktur merupakan cara yang tepat dalam melakukan penelitian kualitatif. Terdapat beberapa ciri dari wawancara semistruktur yaitu pertanyaan terbuka namun ada batasannya, durasi wawancara yang dapat diprediksi, fleksibel tetapi terkontrol, terdapat pedoman dalam melakukan wawancara, dan tujuan wawancara untuk mengetahui fenomena tertentu.

Data sekunder diperoleh dari PT JIExpo dan media lain yang dapat mendukung dan memperkuat hasil dari penelitian yang dilakukan. Menurut Herdiansyah (2012), studi dokumentasi merupakan metode pengumpulan data kualitatif dengan mengumpulkan, melihat, dan menganalisis data dari dokumen-dokumen yang ada. Penelitian juga menggunakan kajian pustaka yang dilakukan peneliti tidak dari sumber langsung namun dari hasil penelitian terdahulu atau dari sumber kedua, seperti buku, artikel online, literatur, dokumentasi (Hermawan, 2009).

Triangulasi sumber data digunakan untuk validasi data yang diperoleh. Triangulasi sumber data merupakan penggalian informasi tertentu melalui berbagai metode dan sumber data, seperti melalui wawancara, observasi atau dokumen tertulis. Masing-masing cara dapat menghasilkan data yang berbeda sehingga dapat memberikan padangan yang berbeda mengenai fenomena yang diteliti. Berbagai pandangan itu dapat menciptakan keluasan pengetahuan untuk memperoleh kebenaran andal (Pawito, 2008).

Dapat disimpulkan bahwa penelitian kualitatif mengharuskan seorang peneliti untuk menjadi seorang informan yang bisa memberikan informasi yang akurat. Untuk itu peneliti harus terjun langsung ke lapangan dengan melakukan observasi secara langsung dan melakukan wawancara dengan sumber informan yang bekerja bersama di lapangan. Observasi penelitian dibagi menjadi dua, yaitu observasi partisipan dan observasi nonpartisipan. Obeservasi partisipan adalah metode observasi yang melaluinya peneliti berfungsi juga sebagai partisipan dan ikut serta dalam kegiatan yang dilakukan oleh kelompok yang diteliti. Sedangkan observasi nonpartisipan merupakan metode observasi yang melaluinya peneliti hanya bertindak mengobservasi tanpa ikut terjun melakukan aktivitas yang dilakukan oleh kelompok yang diteliti, baik kehadirannya diketahui maupun tidak diketahui (Kriyantono, 2010).

Dalam melakukan suatu penelitian penulis harus dapat melakukan pengecekan mengenai keabsahan data yang telah diperoleh. Pada penelitian ini digunakan pengecekan data melalui validitas triangulasi. Keabsahan data merupakan konsep penting yang diperbarui dari konsep kesahihan (validitas) dan keandalan (reliabilitas) menurut versi positivisme dan disesuaikan dengan tuntutan 
pengetahuan, kriteria, dan paradigmanya sendiri (Moleong, 2004). Menurut Moleong (2004), triangulasi merupakan salah satu cara terbaik yang digunakan untuk menghilangkan perbedaanperbedaan dalam proses pengumpulan data mengenai suatu kejadian dan hubungan. Maka dari itu, pengecekan ulang melalui berbagai sumber, metode, atau teori dapat dilakukan. Hal itu dapat dilakukan dengan mengajukan berbagai macam variasi pertanyaan, mengecek berbagai sumber, memanfaatkan metode agar dapat melakukan pengecekan kepercayaan.

Analisis data dalam penelitian ini dilakukan dengan reduksi data dari semua data yang diperoleh, kemudian menampilan data yang diperlukan sesuai dengan kelompok, dan penarikan simpulan dari data yang sudah dikelompokkan. Menurut Miles dan Huberman (dalam Elvinaro, 2010), ada tiga jenis dalam analisis data. Pertama, reduksi adalah suatu bentuk analisis yang dapat mempertajam, memilih, memfokuskan, membuang, menyusun data dalam suatu cara yang simpulan akhirnya dapat digambarkan. Reduksi data dilakukan secara berkelanjutan sampai laporan akhir. Bahkan sebelum data secara aktual dikumpulkan, reduksi data antisipasi terjadi sebagaimana diputuskan oleh peneliti. Kemudian, data display dapat diartikan sebagai suatu kumpulan informasi yang tersusun dan membolehkan pendeskripsian simpulan dan pengambilan tindakan. Bentuk penulisan yang biasanya digunakan dalam metode kualitatif yaitu berbentuk teks naratif. Selanjutnya dilakukan penarikan/verifikasi simpulan.

\section{HASIL DAN PEMBAHASAN}

Pekan Raya Jakarta merupakan event yang diselenggarakan setiap tahun untuk memperingati hari jadi kota Jakarta, 22 Juni. Kemudian event ini juga merupakan salah satu bentuk komunikasi tentang pembangunan daerah yang ditujukan kepada masyarakat Jakarta, Bogor, dan Bekasi pada khususnya dan Masyarakat Indonesia pada umumnya. Penyelenggaraan Pekan Raya Jakarta selalu bertepatan dengan libur sekolah sehingga memungkinkan pengunjung dari berbagai daerah di Indonesia datang untuk menyaksikan.

Komunikasi yang digunakan PRJ yaitu komunikasi verbal dan nonverbal. Komunikasi verbal dilakukan oleh Sales Promotion Girl yang menawarkan langsung produk atau jasa dari perusahaan yang diwakilikinya. Sedangkan komunikasi nonverbal menggunakan gerak-gerik (movement), seperti terlihat di PRJ banyak badut lucu yang mencerminkan ikon suatu produk. Komunikasi nonverbal dapat juga disampaikan melalui display dari barang-barang yang dipromosikan, termasuk di dalamnya pakaian seksi yang dikenakan pramuniaga (SPG). Selain itu, komunikasi nonverbal dapat ditunjukkan dengan suasana yang di arena PRJ melalui musik dan dekorasi yang memikat (Nurjaman \& Umam, 2012).

Event PRJ juga dapat dikategorikan sebagai special event atau ajang khusus. Ajang khusus ini menurut Shone dan Parry (dalam Pudjiastuti, 2010) memiliki karakteristik, antara lain: unik, terdapat personal interaksi, membangun suasana dan service yang memuaskan, ada ritual (ceremony), mempunyai jadwal tetap dan padat karya yang menjadi tujuan dari penyelenggara. Sementara itu, Allen, dkk (2005) menggambarkan bahwa istilah special event dibuat untuk ritual khusus, ada presentations, performance, atau celeberations yang direncanakan dan dibuat pada acara-acara khusus atau untuk kegiatan yang bertujuan sosial dan budaya. Allen, dkk (2005) juga menyimpulkan bahwa special event dibuat dengan peran penuh dari masyarakat. Dengan demikian, dari beberapa pendapat, dapat diketahui bahwa event PRJ termasuk salah satu spesial event karena dibuat sebagai ritual memperingati HUT Jakarta setiap tahun. Pada event ini terdapat seperti yang disebutkan oleh Allen ada presentasi produk, ada penampilan panggung, dan upacara untuk seleberasi. 
Menjawab permasalahan mengenai keinginan dari pihak Pemprov DKI yang mengevaluasi kegiatan Pekan Raya Jakarta dapat dijelaskan bahwa memang event tahunan tersebut menjadi ajang promosi produk dan dapat juga digolongkan sebagai event sponsorship. Wilcox, dkk (2011) menyatakan bahwa event sponsorship merupakan sarana untuk meningkatkan penjualan, memperluas pasar, dan meningkatkan pendapatan melalui kegiatan sosial. Dengan demikian, dari sisi kategori event PRJ merupakan event sponsorship. Menurut Wilcox, dkk. (2011) event merupakan bentuk kegiatan untuk mempertemukan antara konsumen dengan aneka macam merek. Event juga dapat dijadikan ajang untuk memperkenalkan konsumen kepada produk baru. Pada Pekan Raya Jakarta dapat dilihat banyak promosi produk yang ditawarkan dan bahkan dengan berbagai hadiah. Sebagai contoh adalah produk minuman.

Komunikasi pemasaran yang dilakukan pihak penyelenggara dapat dinyatakan berhasil. "Jumlah pengunjung tahun ini telah melebihi jumlah pengunjung tahun lalu, yaitu telah mencapai 4,8 juta orang sampai dengan Sabtu (6/6/2013). Hal itu dikarenakan kami ada memberikan fasilitas gratis untuk lansia, TNI/Polri, anak-anak dan para undangan," kata Murdaya dalam kata sambutannya (Rudi, 2013). Hal serupa juga diungkapkan oleh Tandy (2013) yang mengungkapkan bahwa sebuah event perlu melakukan komunikasi untuk melihat proses pada perencanaan dan pelaksanan event. Dibanding dengan tahun sebelumnya, penyelenggaraan Jakarta Fair 2012, jumlah pengunjung mencapai 4,5 juta orang dengan total transaksi mencapai Rp4,2 triliun. Tahun 2013 total transaksi meningkat hingga Rp4,5 triliun sesuai dengan target dan sektor otomotif sebagai penyumbang jumlah transaksi paling banyak. (Rudi, 2013)

Melalui Tempo (2013), Pekan Raya Jakarta mengomunikasikan jadwal panggung musik yang akan ditampilkan. Jakarta Fair berlangsung dari 6 Juni 2013 sampai 7 Juli 2013 dengan Tiket masuk yang dikenakan adalah Rp 25 ribu untuk Senin sampai Kamis, dan Rp 30 ribu untuk Jumat sampai Minggu atau hari libur. Konser musik JIExpo (Tempo, 2013) berlangsung selama 32 hari nonstop sejak 6 Juni hingga 7 Juli 2013. Di setiap panggung, pada setiap malam akan tampil satu band/penyanyi utama, didahului oleh 3 sampai 4 band pembuka. Nama-nama besar musisi Indonesia tampil dalam pergelaran konser musik paling lengkap dan dengan durasi penyelenggaraan paling lama di Asia tersebut. Hampir 200 group band pendatang baru dan indie-band akan tampil. Konser musik bertema 'Aku Cinta Musik Indonesia' ini, mewajibkan semua band dan penyanyi membawakan salah satu lagu wajib/lagu nasional dengan iringan musik sesuai genre mereka. Slogan-slogan cinta musik Indonesia dan anti pembajakan akan diumumkan para penampil maupun oleh MC. Panggung JIExpo Music Concert dibagi dalam dua bagian, yaitu panggung utama di open space Arena PRJ Kemayoran, dan panggung budaya di Gambir Expo Arena PRJ Kemayoran. Panggung utama menampung 10 ribu penonton, dan panggung budaya menampung sekitar 3 ribu penonton. Panggung utama dibuka setiap hari sejak pukul 19.00 hingga pukul 22.00 WIB.

\section{Perbedaan Pemahaman antara PT JIExpo dengan Pemprov DKI}

Winarno (2013) menulis Pekan Raya Jakarta (PRJ) digelar pertama kali di Kawasan Monas pada 5 Juni hingga 20 Juli 1968 dan dibuka Presiden Soeharto dengan melepas merpati pos. Ide penyelenggaran event ini pertama kali digagas Syamsudin Mangan (Haji Mangan), pengusaha tekstil dan ketua KADIN (Kamar Dagang dan Industri). Ia mengusulkan suatu ajang pameran besar untuk meningkatkan pemasaran produksi dalam negeri yang kala itu sedang mulai bangkit pasca-G30S/1965 kepada Gubernur DKI Jakarta. Saat itu (1967) Gubernur DKI Jakarta dijabat Ali Sadikin, atau yang lebih dikenal Bang Ali. Haji Mangan terinspirasi dari berbagai event pameran internasional yang sering diikutinya sebagai seorang konglomerat bidang tekstil kala itu dan pasar malam Gambir yang dari dulu sudah ramai dikunjungi. Pemerintah DKI Jakarta kala itu langsung membentuk panitia sementara yang dipercayakan kepada Kamar Dagang dan Industri (KADIN), dengan Haji Mangan sebagai ketua. 
Gagasan Haji Mangan ini sesuai keinginan pemerintah DKI yang ingin membuat suatu pameran besar yang terpusat dan berlangsung dalam waktu yang lama. Keinginan itu merupakan upaya mewujudkan keinginan pemerintah DKI Jakarta yang ingin menyatukan berbagai pasar malam. Ketika itu pasar malam masih menyebar di sejumlah wilayah Jakarta. Contohnya adalah pasar malam Gambir yang tiap tahun berlangsung di bekas Lapangan Ikada-sekarang kawasan Monas. Hal-hal tersebut merupakan inspirasi dari pameran yang diklaim sebagai pameran terbesar ini.

Event tersebut disahkan Pemerintah DKI dengan mengeluarkan Peraturan Daerah (Perda) No. 8 tahun 1968 yang antara lain menetapkan bahwa PRJ akan menjadi agenda tetap tahunan dan diselenggarakan menjelang Hari Ulang Tahun Jakarta yang dirayakan setiap tanggal 22 Juni. Sebuah yayasan yang diberikan nama Yayasan Penyelenggara Pameran dan Pekan Raya Jakarta juga dibentuk sebagai badan pengelola PRJ. Sesuai Perda No. 8/1968 tersebut tugas yayasan ini tidak hanya menyelenggarakan PRJ saja tetapi juga sebagai penyelenggara Arena Promosi dan Hiburan Jakarta (APHJ) yang dijadwalkan berlangsung sepanjang tahun.

Pekan Raya Jakarta (PRJ) atau Jakarta Fair adalah pameran tahunan terbesar di Indonesia. Walaupun dinamai pekan, acara ini biasanya berlangsung selama satu bulan penuh dari pertengahan Juni sampai pertengahan Juli untuk memperingati hari jadi kota Jakarta. PRJ pertama diadakan pada 1968. Sampai saat ini setiap tahun penyelenggaraannya tidak pernah terputus. Dari 1968 sampai 1991 PRJ pernah berlangsung di Taman Monumen Nasional.

Event Jakarta Fair 2013 berlangsung selama kurang lebih 1 bulan. Konsep event tersebut menurut Gubenur Jakarta, Joko Widodo, tidak lagi mengusung budaya Betawi dan mengutamakan masyarakat kecil seperti awal event itu diadakan. Lantas, Jumat, 14 Juni 2013 lalu PRJ tandingan pun digelar di Monas bertajuk pameran Pekan Produk Kreatif Daerah 2013 oleh Provinsi DKI Jakarta. Pembukaan acara tersebut dilakukan Wakil Gubernur DKI Jakarta Basuki Tjahaja Purnama di Monas, Jakarta.

Pemprov DKI Jakarta (Aziza, 2013) memikirkan agar Jakarta Fair yang biasa digelar di JIExpo Kemayoran pindah ke Monas. Sebagai uji coba, Pemprov akan menggelar Pekan Produk Kreatif Daerah (PPKD) 2013, yang dianggap sebagai embrio PRJ yang baru, di Monas. PPKD 2013 ini telah diselenggarakan dari 14 Juni hingga 16 Juni 2013 di Lapangan Silang Monas Barat Daya (pintu masuk Tugu Kuda), Jakarta Pusat. Kepala Dinas Perindustrian dan Energi DKI sekaligus Ketua Penyelenggara PPKD 2013 Andi Baso Mappapoleonro mengatakan, PPKD 2013 merupakan salah satu acara dalam rangka memeriahkan Hari Jadi Ke-486 Provinsi DKI Jakarta. Event PPKD yang telah dikemas dengan pagelaran seni dan budaya dapat menjadi sebuah event yang menarik dan ditunggu oleh masyarakat. Pada akhirnya mampu meningkatkan ekonomi dan kesejahteraan warga Jakarta nantinya. "PPKD 2013 merupakan sarana promosi dan kegiatan untuk mendorong terciptanya berbagai karya kreatif di Jakarta sesuai dengan keunggulan sumber daya manusia (SDM), kreativitasnya, serta budaya yang dimiliki di masing-masing wilayah,” kata Andi Baso di Balaikota Jakarta, Rabu (12/6/2013). (Aziza, 2013)

Hal tersebut di atas senada dengan pernyataan Caust dan Glow (2011) yang mengungkapkan peran Fringe Festival Adelaide dalam memfasilitasi wirausaha di kalangan seniman untuk berpartisipasi. Caranya dengan menelusuri perkembangan kemampusan gagasan dari pengusaha, mengidentifikasi cara wirausaha untuk berperan dalam wacana industri kreatif. Mereka mencatat bahwa wirausaha merupakan strategi kunci dalam kerangka industri kreatif, maka muncul bagi konsep seniman yang tidak selalu berkonotasi pada pencapaian hasil komersial. Budaya pengusaha ditentukan oleh kemandirian, fokus pada pengembangan kerajinan mereka, dan nilai budaya kerja mereka (Caust \& Glow, 2011).

Dalam tulisan Tempo (1/12/2012) event tersebut diselenggarakan karena Wakil Gubernur DKI Jakarta Basuki Tjahaja Purnama merasa DKI Jakarta dikadalin oleh penyelenggara Pekan Raya 
Jakarta. Dia mengancam akan mencabut kerja sama dengan penyelenggara kalau tetap menarik dana Rp 4 miliar kepada pemerintah provinsi. Menurut Ahok, sewajarnya, sebagai tuan rumah, DKI Jakarta mendapat keuntungan dari pelaksanaan PRJ, bukannya malah kena biaya sewa Rp 4 miliar. "Semestinya, kalau kita minta Rp 10 miliar, pasti bos PRJ kasih, benar enggak?" kata Ahok dalam sebuah rapat. Ahok mengatakan untuk meminta KPK dan BPK mengaudit penyelenggara PRJ yang selama ini dipegang PT Jakarta International Expo (JIExpo).

\section{Krisis Citra Pekan Raya Jakarta}

Citra menurut Arker dan Mayer dalam Nova (2011) merupakan suatu anggapan, impresi atau gambaran oleh orang maupun kelompok mengenai suatu objek. Sedangkan Nova (2011) mengartikan citra adalah total persepsi terhadap suatu objek yang terbentuk dengan memproses informasi terkini dari beberapa sumber setiap waktu. Jika dikaitkan dengan citra, penyelenggaraan Pekan Raya Jakarta oleh JIExpo dipandang negatif oleh Pemprov DKI. Itu karena tidak ada dialog yang intensif antara kedua belah pihak sehingga menimbulkan ketegangan antara kedua belah pihak.

Kriyantono (2012) mengungkapkan bahwa krisis yang terjadi membutuhkan respons yang cepat dan sistematis. Namun situasi demikian yang dinilai sebagai situasi yang membahayakan dapat diatasi dengan menggunakan prosedur atau mekanisme normal sehingga penyebab dan akibat yang ditimbulkan dapat diprekdisi. Kaitannya dengan masalah yang dihadapi Pemprov DKI yang menghendaki PT JIExpo kembali ke konsep awal yang menunjang perekonomian rakyat kecil dapat diatasi dengan upaya membuat peraturan daerah yang baru untuk penyelenggaraan event PRJ tersebut.

Pemerintah DKI Jakarta menyatakan kekecewaannya terhadap penyelenggara dan mengungkapkan keinginannya untuk mengembalikan arena pekan raya untuk memeriahkan ulang tahun Jakarta ke kawasan Monas. Ahok yang dilansir oleh Tempo.com, menegaskan bahwa Pemprov DKI Jakarta akan mengevaluasi Peraturan Daerah Nomor 12 Tahun 1991 tentang Penyelenggaraan Pekan Raya Jakarta. Wakil Gubernur DKI Jakarta Basuki "Ahok" Tjahaja Purnama mengatakan evaluasi ini dilakukan salah satunya untuk memberi kesempatan keikutsertaan usaha mikro, kecil, dan menengah. "Lihat saja sekarang, kerak telur saja tidak dapat tempat," kata Ahok di Balai Kota, Rabu, 5 Juni 2013. Proses evaluasi Perda ini diserahkan kepada Asisten Bidang Pariwisata. "Juga agar produk kreatif bisa masuk."

Di bagian lain dalam Hilal (2013), “Gubernur ingin PRJ tidak terlalu elit dan tidak berbayar. Kalau sekarang, yang bisa masuk ke Jakarta Fair itu kalangan atas. Yang kalangan bawah tidak bisa menikmati--tidak bisa menikmati HUT Jakarta," kata Ahok, Senin (3/6). Meski tahun depan Jakarta Fair tidak dipegang PT JIExpo, Ahok menegaskan tidak akan menggugat JiExpo terkait 13,1 persen saham Pemprov DKI yang ada di PT JIExpo. Dalam RUPS PT JIExpo beberapa waktu lalu telah disepakati adanya pembagian dividen kepada seluruh pemegang saham. Dividen yang mencapai Rp10 miliar itu akan dibagikan kepada Pemprov DKI sebesar saham yang dimiliki, yakni 13,1 persen. Tepatnya, Rp1,7 miliar.

Ahok menegaskan, Pemprov DKI tidak mengubah acara yang diselenggarakan oleh JIExpo sejak 2005 itu. Namun Pemprov DKI tetap akan meyelenggarakan acara yang sama dengan berbasis kerakyatan. "Selama HUT DKI, apa saja bisa kami lakukan. Kami boleh dong bikin acara yang berbasis kebudayaan. Itu hak kami," katanya. Tahun ini Pemprov DKI akan menyusun kegiatan festival rakyat di seluruh wilayah Jakarta. Bahkan, dalam merayakan Hari Ulang Tahun (HUT) kota Jakarta, akan dilakukan car free night. "Mulai tahun ini ada festival rakyat di mana-mana, dan akan ada car free night. Jadi, kalau PT JIExpo mau pameran, silakan pameran saja. Kita punya konsep sendiri yang sifatnya kerakyatan,” ujarnya. (Hilal, 2013)

Sedangkan tanggapan dari Pihak PT JIExpo yang diwakili Marketing Director PT JIExpo Ralph Scheunemann (dalam Hilal, 2013) menolak berkomentar soal pemindahan lokasi perhelatan 
Jakarta Fair. "Soal pemindahan tempat dan pengambilalihan pihak penyelenggara yang dinyatakan Wakil Gubernur, saya no comment. Karena, mungkin masih sebatas wacana. Prinsip kami: terserah saja. Silakan Pemprov. membicarakan dan membahas ini. Kami juga akan bahas ini nanti dengan Pemprov,” kata Ralph.

Sebenarnya bila dilihat dari sisi pengunjung, ada beberapa respons positif maupun negatif pada penyelenggaraan Pekan Raya Jakarta. Respons positif dari para pengunjung, mereka tidak terlalu peduli siapa penyelenggara event Pekan Raya Jakarta tersebut. Fenomena yang dapat dilihat bahwa khususnya untuk pasangan muda dan keluarga datang karena ingin menikmati hiburan. Pengunjung anak-anak yang datang selalu mencari arena permainan. Sedangkan para ABG berkeinginan untuk berfoto dengan kamera handphone dengan latar belakang yang menarik dan berpose dengan para artis.

Bila dilihat dari respons negatif pengunjung diungkapkan bahwa PRJ tidaklah terlalu menarik bagi masyarakat yang memang tinggal di kota Jakarta. Ketika pada akhirnya mereka datang karena mereka ingin mengantar anggota keluarga, kenalan, dan sahabat dari daerah yang ingin berkunjung ke PRJ. Respons negatif lainnya ada kesan pengunjung harus ekstra hati-hati jika berada di arena Pekan Raya Jakarta karena kurangnya rasa aman. Banyak copet yang berkeliaran menunggu pengunjung yang lengah.

\section{Penyelenggaraan Pekan Raya Jakarta 2013}

Kegiatan Pekan Raya Jakarta (PRJ) yang terpusat di JIExpo Kemayoran tahun 2013 tidak semeriah tahun-tahun sebelumnya. Iklan yang mempromosikan acara tahunan itu baik di televisi maupun media cetak sangat minim. Banyak pengunjung juga mengakui PRJ JIExpo tahun ini tak semenarik dulu. Bukan cuma pengunjung, pedagang pun mengaku tak dapat meraup untung seperti dulu.

Berikut adalah kesaksian dari seorang pengunjung Pekan Raya Jakarta: "Ramainya gak kaya dulu susah cari parkir, di dalam padat. Sekarang lebih lengang," kata Tya, warga Kelapa Dua, Depok. Rupanya kondisi ini sampai ke telinga Wakil Gubernur DKI Jakarta, Basuki Tjahaja Purnama. Pria yang akrab disapa Ahok itu mengatakan, informasi yang dia dapat PRJ JIExpo Kemayoran tahun ini mengalami penurunan omzet sampai 40 persen dari tahun-tahun sebelumnya.

Jokowi ini menilai, PT JIExpo sebagai lokasi resmi penyelenggaraan PRJ telah memanfaatkan acara itu untuk mencari keuntungan sebesar-besarnya dan hanya memberikan stan pada barang bermerek.Dalam beberapa kesempatan, Jokowi memang menegaskan kegiatan PRJ Kemayoran cuma menguntungkan pihak swasta dalam hal ini Murdaya Poo dan tim. Saking geramnya, Jokowi berencana memutuskan kerjasama Pemprov DKI dengan JIExpo Kemayoran (merdeka.com).

Jokowi yang geram lantas ingin mengembalikan konsep PRJ seperti saat berdiri dahulu. Dia ingin PRJ tak hanya diisi jualan barang mahal, tapi juga memberikan hiburan kesenian tradisional dan kebudayaan nusantara.Oleh karena itu, Jokowi tengah menggagas ide agar PRJ kembali lagi ke lokasi awalnya dahulu di Kompleks Tugu Monas, Jakarta Pusat. Di Monas, konsep PRJ akan dibuat Jokowi lebih merakyat dan tidak menguras kantong pengunjung.

Namun, merdeka.com menuliskan, untuk kesekian kalinya, rencana Jokowi selalu berseberangan dengan mitra kerjanya DPRD DKI. DPRD DKI tak setuju dengan rencana Jokowi memindahkan PRJ ke Monas. Jokowi dinilai punya keinginan tak mendasar. Parahnya lagi, bukan memberi masukan, DPRD malah mencibir rencana Jokowi itu dan lebih berpihak serta membela perusahaan raksasa milik Murdaya Poo: PT JIExpo.

Menurut analisis pengamat perkotaan dari Trisakti, Yayat Supriyatna, PRJ Kemayoran tahun ini memang tak begitu laris manis. Dia yakin ada beberapa faktor penyebab PRJ Kemayoran tak laku 
tahun ini."Yang namanya pekan raya kan bukan semata-mata dagang. Nah semua juga tahu orientasi PRJ Kemayoran itukan bisnis yang cuma pikirkan nilai ekonomi, cuma kemewahan. Dan sayangnya masyarakat sekarang makin cerdas untuk memilih," kata Yayat.

\section{SIMPULAN}

Pekan Produk Kreatif Daerah dapat menjadi alternatif pengganti Pekan Raya Jakarta yang diselenggarakan oleh PT JIExpo. Hal ini terbukti jumlah pengunjung yang di luar bayangan karena mencapai 15 ribu per hari atau sekitar 50 ribu orang selama tiga hari berturut-turut. Sedangkan dahulu, pengunjung hanya sekitar 3.000 orang dalam rentang waktu pelaksanaan yang sama.

Secara akademis, untuk mengatasi krisis komunikasi yang terjadi antara PT JIEXpo dengan Pemprov DKI dapat melakukan pertemuan, guna melakukan identifikasi, membatasi masalah dan menekan agar krisis tidak diperluas dan diakhiri dengan bersama-sama melakukan perbaikan dengan mencari solusi terhadap masalah tersebut. Pemprov DKI, mungkin tidak perlu membuat Pekan Raya tandingan dan tetap memberi kepercayaan pada PT JIExpo untuk melaksanakan event dengan ketentuan-ketentuan baru. Sedangkan untuk saran praktis, Sebaiknya PT JIExpo melakukan Lobby dan negosiasi dengan sikap terbuka kepada pemerintah mengenai cara terbaik yang sama-sama menghasilkan Win-Win Solution bagi kedua pihak. Tidak mudah untuk dilaksanakan tapi perlu diupayakan oleh kedua belah pihak.

\section{DAFTAR PUSTAKA}

Allen, J., O’Toole, Harris, R., McDonnell, I. (2005). Festival And a Special Event Management. 3rd Edition. Melbourne, Australia: John Wiley \& Son.

Aziza, K. S. (2013, 12 Juni). Pemprov DKI Gelar "Embrio PRJ Baru" di Monas. Diakses dari http://megapolitan.kompas.com/read/2013/06/12/16503865/Pemprov.DKI.Gelar.Embrio.PRJ. Baru.di.Monas.

Caust, J., \& Glow, H. (2011). Festivals, Artist, and Entreprenurlism. The Role of Adelaide Fringe Festival. International of Journal Event Management Research, 6(2). Diakses dari http://www.ijemr.org/docs/Vol6-2/CaustGlow.pdf

Elvinaro, A. (2010). Metodologi Penelitian untuk Public Relations Kuantitatif dan Kualitatif. Bandung: Simbiosa Rekatama Media

Herdiansyah, H. (2012). Metodologi Penelitian Kualitatif untuk Ilmu-ilmu Sosial. Jakarta: Salemba Humanika.

Hermawan, A. (2009). Penelitian Bisnis. Jakarta: Grasindo.

Hilal, F. (2013, 4 Juni). PRJ Tidak Merakyat. Diakses dari http://www.jurnas.com/halaman/16/2013$\underline{06-04 / 249683}$

Kriyantono, R. (2010) . Teknik Praktis Riset Komunikasi. Edisi Kelima. Jakarta: Kencana.

Kriyantono, Rachmat, Ph.D. 2012. Edisi Pertama. Public Relations \& Crisis Management. Pendekatan Critical Public Relations Etnografi Kritis \& kualitatif.Jakarta: Kencana Prenada Media Group. 
Moleong, L. J. (2004). Metodologi Penelitian Kualitatif. Bandung: Remaja Rosdakarya.

Nova, F. (2011). Crisis Public Relations. Strategi PR menghadapi krisis, mengelola isu, membangun citra, dan reputasi perusahaan. Cetakan 1. Jakarta: Rajawali Pers.

Nurjaman, K., \& Umam, K. (2012). Komunikasi Public Relations. Bandung: Pustaka Setia.

Pawito. (2008). Penelitian Komunikasi Kualitatif. Yogyakarta: Pelangi Aksara.

Pudjiastuti, W. (2010). Special Event. Alternatif Jitu membidik Pasar. Jakarta: Elex Media Komputindo.

Rudi, A. (2013, 7 Juli). JIExpo: Pengunjung Jakarta Fair 2013 Meningkat. Diakses dari http://megapolitan.kompas.com/read/2013/07/07/2140397/JIExpo.Pengunjung.Jakarta.Fair.20 13.Meningkat

Tandy, G. S. (2013). Evaluasi Special Event Surabaya Fashion Parade 2012 yang Diselenggarakan oleh Tunjungan Plaza Surabaya. Jurnal E-Komunikasi. Program Studi Ilmu Komunikasi. Universitas Kristen Petra Surabaya. Diakses dari http://www.google.co.id/url?sa=t\&rct=j\&q=\&esrc=s\&source=web\&cd=2\&ved=0CC4QFjAB \&url=http\%3A\%2F\%2Fstudentjournal.petra.ac.id\%2Findex.php\%2Filmukomunikasi\%2Farticle\%2Fdownload\%2F928\%2F828\&ei=7EotU7XWHYSKrgfo9oGYCg\&u sg=AFQjCNGL--POTnNyuX2AxMujXM7zzxHXMw

Tempo. (2013). Jadwal Penyanyi yang Tampil di Jakarta Fair 2013. Diakses dari http://www.tempo.co/read/news/2013/06/09/113486776/Jadwal-Penyanyi-yang-Tampil-diJakarta-Fair-2013

Tempo. (2013). Gonjang-ganjing Pekan Raya Jakarta (Bukan) Cuma Isu. Diakses dari http://koran.tempo.co/konten/2013/06/12/312494/Gonjang-ganjing-Pekan-Raya-JakartaBukan-Cuma-Isu

West, R., \& Turner, L. H. (2007). Pengantar Teori Komunikasi: Analisis dan Aplikasi. Buku ke-1. Terj: Maria Natalia Damayanti Maer. Jakarta: Salemba Humanika.

Wilcox, D. L., Cameron, G. T., Reber, B. H., \& Jae-Hwa Shin. (2011). Think Public Relations. Boston: Pearson Education.

Winarno, H. H. (2013, 7 Juni). Kisah Haji Mangan dan sejarah Pekan Raya Jakarta. Diakses dari http://m.merdeka.com/jakarta/kisah-haji-mangan-dan-sejarah-pekan-raya-jakarta.html 